\title{
The Effect of Papaya Seed Ethanol Extract in Vivo on The Number of Osteoblasts Cells of Periodontitis-Induced Rats
}

\author{
Ratih Pusporini ${ }^{*}$, Ahmad Basori ${ }^{2}$, Agung Krismariono ${ }^{3}$ \\ ${ }^{1}$ Department of Oral Biology, Faculty of Dentistry, Universitas Brawijaya \\ 2Department of Pharmacology, Faculty of Medicine, Universitas Airlangga \\ ${ }^{3}$ Department of Periodontics, Faculty of Dentistry, Universitas Airlangga
}

\begin{abstract}
The papaya seed ethanol extract is rich in antioxidant ingredients, such as flavonoids and phenolic acids. One of the main factors causing chronic inflammatory in periodontitis is oxidative stress. Administration of papaya seed extract is assumed to increase the number of rat osteoblast cells induced periodontitis. This research was conducted to analyze the effect of papaya seed extract on osteoblasts cells of rat induced periodontitis. This research represented an experimental laboratory-based investigation involving 35 rats of the Rattus norvegicus strain divided into 5 treatment groups (K, P1, P2, P3, P4). Control group $(\mathrm{K})$ was not induced by periodontitis and was not given an extract, while group $\mathrm{P}$ induced periodontitis using LPS Phorphyromonas gingivalis (P.gingivalis) for 7 days and continued wire mesh installation around the mandibular incisors in the form of number "8" for 7 days. P1 group was given feed only without extract, while the rest were given extract of $200 \mathrm{mg} / \mathrm{kgBB}, 300 \mathrm{mg} / \mathrm{kgBB}$, and $400 \mathrm{mg} / \mathrm{kgBB}$. The data obtained were analyzed with a one-way ANOVA test. The results showed that the average number of osteoblasts varied significantly between the groups. There was an increase in the average number of osteoblast cells in rat induced periodontitis after given papaya seed extract.
\end{abstract}

Keywords: periodontitis, papaya seed extract, osteoblast, flavonoid, phenolic acid

\section{INTRODUCTION}

Periodontitis is a chronic inflammatory disease triggered by bacteria that progressively damage the connective tissues and alveolar bones and is the most common cause of tooth loss experienced by adults ${ }^{1,2}$. According to Yoshida et al., tooth loss is one of the risk factors of cerebral stroke ${ }^{3}$. It is estimated that $40-90 \%$ of the global population suffer from periodontitis, therefore, it is an epidemic with the highest prevalence worldwide 4 .

Thus far, antibiotic is used as a therapy of periodontitis in order to cope with the infection caused by the bacteria, however, the systemic use of antibiotic is quite disadvantaging due to the distribution toward other parts of the body that do not need it. Antibiotic can also create a resistance, change in the composition of the normal oral flora, vomiting, diarrhea, and tooth color change ${ }^{4,5}$.

The alternatives to the antibiotic as a periodontitis therapy is constantly developed, one of them is the herbal materials from papaya. The potentials of papaya ethnobotanics have been known for a long time, including the steam of boiled papaya leaves used as a cure to toothache ${ }^{6,7}$. Apart from the leaves, papaya seed that is considered waste has components of polyphenols (phenolic acids and flavonoids) even more than the

*Corresponding author : Ratih Pusporini

Email : ratih.fk@ub.ac.id edible part of papaya. Papaya seed also contains alkaloids, saponins, tannins, and phenols. The total antioxidant activities of papaya seed ethanol extract are as much as $912,77 \mathrm{~g} \mathrm{GAE} / \mathrm{g}$ dry extract $8,9,10$.

The periodontal tissues include the alveolar bones, which balance is maintained by the intercellular communication between osteoblasts and osteoclasts. In the case of pro-osteoblast expression less than the formulation of osteoclasts, there will be an increase in bone resorption. Therefore, the intercellular communication between osteoblasts and osteoclasts is imperative in maintaining the status of bone homeostasis ${ }^{11}$. Chen et al., stated that the administration of phenolic acids from blueberry plants can increase the osteoblasts differentiation and proliferation ${ }^{12}$. From the explanation above, it is proven that papaya seed is a waste despite containing potentials of anti-inflammation and antioxidant. To date, the influence of papaya seed extract to osteoblast cells of periodontitis rats has not been explored, therefore, research on papaya seeds related to the cure of periodontitis is required. This study is aimed to analyze the influence of papaya seed extract toward the number of rat's osteoblast cells that are induced with periodontitis. The findings are expected to be beneficial as a reference to the development of papaya extract seed into an alternative therapy for periodontitis. 
Table I. Mean and Deviation Standard of Osteoblast Cells

\begin{tabular}{clc}
\hline Group & n & Mean $\mathbf{\text { Standard deviation }}$ \\
\hline K & 6 & $111 \pm 28.27$ \\
P1 & 7 & $152.3 \pm 19.86$ \\
P2 & 7 & $161.7 \pm 36.3$ \\
P4 & 7 & $164.3 \pm 55.77$ \\
\hline
\end{tabular}

Table II. The Result of Data Normality Test

\begin{tabular}{llllll}
\hline & Control & P1 & P2 & P3 & P4 \\
\hline Osteoblasts (Sig.) & .322 & .995 & .457 & .994 & .993 \\
\hline
\end{tabular}

\section{METHODOLOGY \\ Materials}

LPS P. gingivalis, ligature wire 0,01", papaya seed, aqua demineralisata, ethanol 70\%, chloroform, formalin buffer $10 \%$, fixation material, HE dye, an immunohistochemical kit of IL-1 $\beta$ rat. The instruments used are adjusted to the research steps. Generally, the equipment is in accordance with the standard of laboratory equipment, including cage, water bottle, cage shelves, husk, and digital scales. Disposable $1 \mathrm{ml}$ syringe, measuring pipette, micropipette. Blenders, digital scales, jars, stirring rods, funnels, stirrers, measuring cups, Erlenmeyer, napkins, filter paper, porcelain saucers, rotary evaporator/water bath, oven. Sonde, measuring pipette. Cotton, jars, work desks, slide-closed containers, cover glass, and microscopes.

\section{Methods}

The design of this study is an experimental laboratory with a research type of the posttestonly control group design. In the experiment unit, it is chosen healthy Wistar strain male rats aged 23 months, weighted 180-200 grams as many as 35 rats divided into five groups (K, P1, P2, P3, P4). The Control Group (K) which is not induced with periodontitis and not given the extract, while the treatment groups (P1, P2, P3, P4) are induced with the LPS Phorphyromonas gingivalis (P.gingivalis) for 7 days and continued with an installment and followed by an installment of thin wire around the mandibular incisors shaped the number "8" for 7 days. The group P1 is given food only without the extract, while the rest are given the extract within the dose of $200 \mathrm{mg} / \mathrm{kgBB}$ (P2), 300 mg / $\mathrm{kgBB}$ (P3), and 400mg / kgBB (P4) per day. On the 30th day, the rats go through euthanasia and the mandibular bones are taken, then the transversal cut of the alveolar bones around the lower jaw incisors are processed for the staining of Hematoxylin-Eosin. All of the treatment to the experimental animals have been approved by the Committee of Ethics of Faculty of Dentistry, Universitas Airlangga No. 004/HRECC.FDOM/I/2017.

\section{Periodontitis induction}

The rats are induced with periodontitis by dropping the LPS $P$. gingivalis on the gingival sulcus around the buccal area of the central mandibular of the lower incisors about $5 \mu \mathrm{g}$ in 0,05 ml PBS once a day for 7 days $^{11}$. Furthermore, on the 8th day, the induction is continued by using an 0.01 " ligature wire hooked on the two mandibular incisors shaping the number eight for 7 days, modifying the research by Ionel et al., which used silk ligature. ${ }^{13}$ The indication of periodontitis is observed at the end of induction by looking at the reddish, swelling, attachment loss to the gingiva, and pocket depth. In order to acknowledge the depth of the pocket, it is measured the distance between the free gingival margin to the bottom of the pocket and the cementoenamel junction to the gutta-percha, if the pocket depth is between 1-2 $\mathrm{mm}$, then it is categorized as periodontitis ${ }^{14}$.

\section{Papaya Seed Extraction}

The papaya seed ethanol extract is made from the seed of ripe Carica papaya Linn, which color is dark brown. The seed is dried in the room temperature, kept safe from direct sun ray, then processed further into the extract in Materia Medika, Batu-Malang. The damp papaya seed is then washed using water twice. Furthermore, the papaya seed is aired in the room temperature for 4 weeks and then blended to shrink the size. 500 grams of the papaya seed powder is macerated with $70 \%$ alcohol solution for three days and then filtered using white cotton fabric and Buchner funnel. The filtration is then evaporated until reaching the optimum level of dryness on the temperature of $40^{\circ} \mathrm{C}$ until producing the thick extract that smells sweet and brown in a 


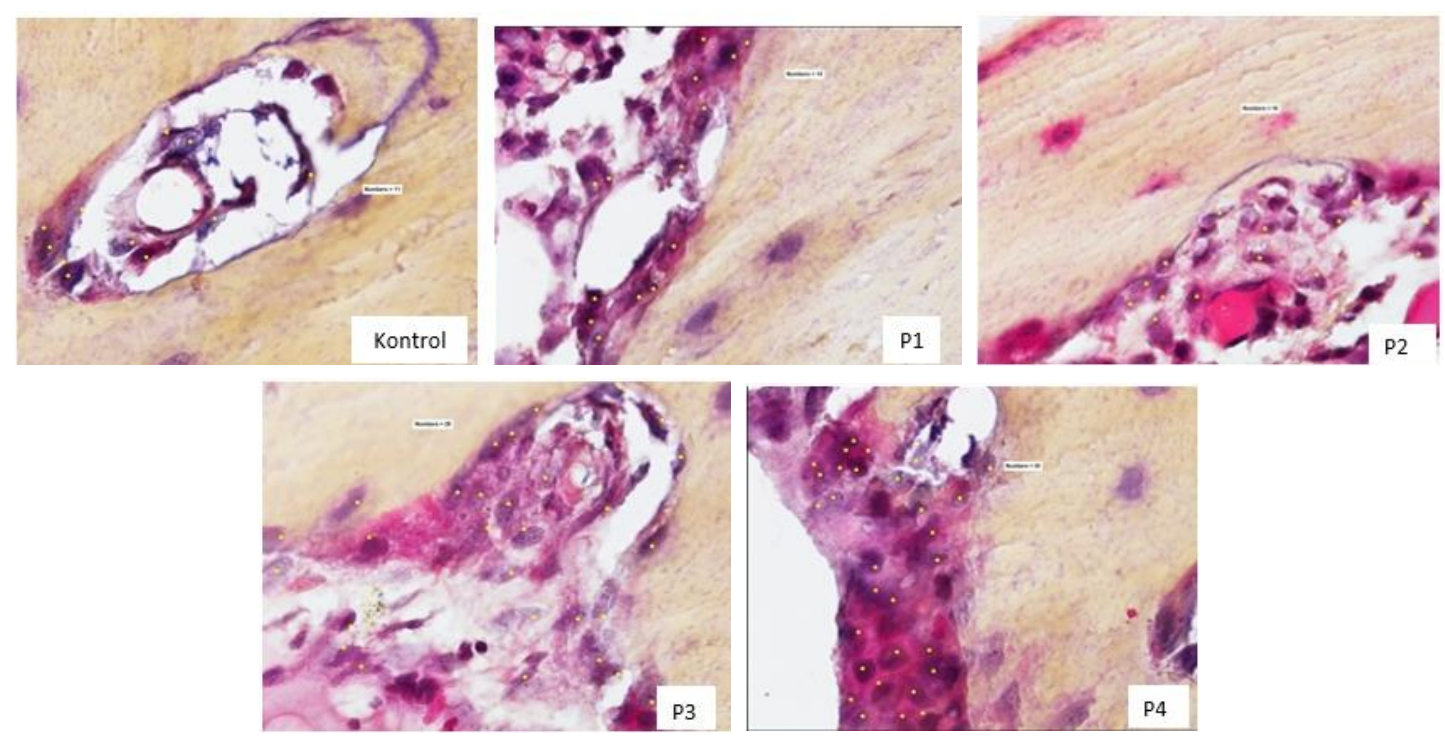

Figure 1. The depiction of osteoblast cells with Hematoxylin Eosin staining in one of the fields of view (yellow dot marks).

form of $24.0 \%$ solidity $(\mathrm{w} / \mathrm{w})$. The extraction process is repeated four times and the solid powder produced is weighted afterward, kept on an airtight and waterproof container, and then inserted to a refrigerator in a temperature of $4^{\circ} \mathrm{C}^{15}$.

\section{Extract administration}

The extract is given to the groups of P2, P3, and $\mathrm{P} 4$ for 15 days orally using a sonde started from the 15th day, once a day at $08.00-09.00$ WIB. After given the papaya seed extract for 15 days, the rats have euthanasia with chloroform through inhalation. The rats' mandibular bones are fixated with a solution of formalin buffer $10 \%$ to make it a paraffin block preparation. The tissues are decalcified by the solution of EDTA $10 \%$ for 30 days within the room temperature and the solution is replaced daily. Furthermore, the area near the gingival sulcus is cut with a thickness of about 2-3 $\mathrm{mm}$ and processed using the Automatic tissue tex processor for 90 minutes. Next, the tissues are processed further for the Hematoxylin-Eosin staining.

\section{Data Analysis}

The normality test is conducted to investigate whether the data that will be analyzed distribute normally or not. The normality test on the data as the result of the calculation of the average osteoblasts indicates that all the data distribute normally $(p>0.05)$ (Table II).

The homogeneity test is conducted to acknowledge whether the data that will be analyzed are homogenous or not. The homogeneity test toward the data as the result of the average number of osteoblasts found Sig. 0.56. Based on the result, it can be seen that all data of average osteoblasts are homogenous data due to the value of $p>0.05$, therefore it was then conducted a test of one-way ANOVA and acquired the result of Sig. 0.029 . According to the finding, it is acknowledged that the overall data of average osteoblasts on every control and treatment groups have meaningful differences, this is shown by the value of $\mathrm{p}<0.05$.

\section{RESULTS AND DISCUSSION}

The variable examined in this research is the osteoblast cells, which are the cell in a form of cuboid located in the bone surface. The data on the number of osteoblast cells is acquired by calculating the number of total cells observed in the 5 different fields of view (FoV) on the magnification of 1000x (Figure 1).

The data of total osteoblast cells is obtained by calculating the number of total cells observed in the different 5 fields of view (FoV) with a magnification of $1000 x$. The formal data is tabulated and analyzed statistically with the help of a computer (SPSS program). The tabulation of data as the result of the calculation of the average number of osteoblasts and its deviation standard can be mapped through the bar chart (Figure 2).

According to the graphic above, it is known that the mean of osteoblasts found that the groups of extract within the dose of $400 \mathrm{mg} / \mathrm{kgBB}$ have the highest mean, which is 175 . 


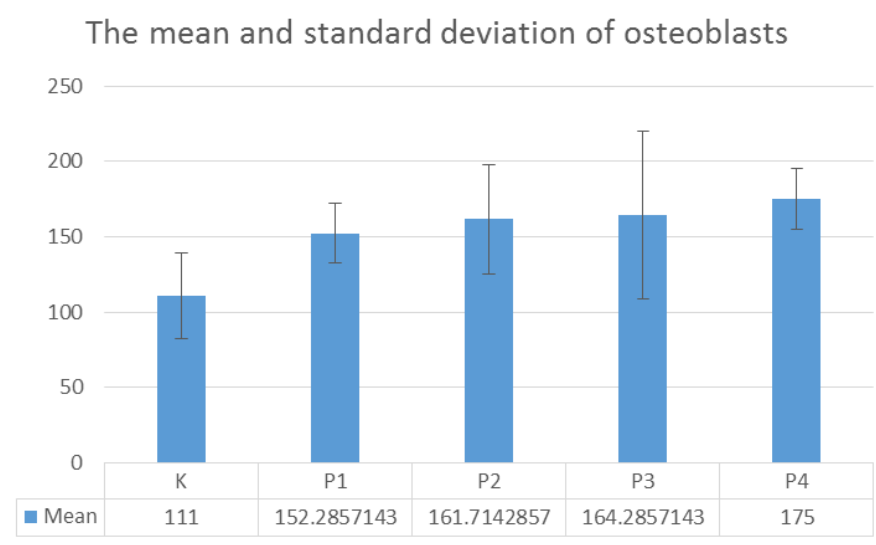

Figure 2. Graphic of the mean and standard deviation of osteoblast cells

Periodontitis is a chronic inflammatory disease triggered by bacteria that progressively damage the connective tissues and alveolar bones. In this research, it is used an induction by dropping the LPS $P$. gingivalis on the gingival sulcus around the buccal area of the central mandibular of the lower incisors about $5 \mu \mathrm{g}$ in 0,05 ml PBS once a day for 7 days $^{16}$. P. Gingivalis is the main pathogen of periodontitis that is closely related to aggressive periodontitis or chronic periodontitis. Lipopolysaccharide (LPS) is a component of the gram-negative bacterial cell's external membrane that has an important role in initiating the inflammative reaction by triggering the production of pro-inflammatory cytokines, such as the interleukin-1 b (IL-1b), IL-6, and IL-8 which later cause the alveolar bone resorption and damage the periodontal tissues. ${ }^{12,17}$

After 7 days of induction using LPS P. gingivalis, there had been no condition of chronic periodontitis but gingivitis. Therefore, the induction is continued by using an 0.01 " ligature wire hooked on the two mandibular incisors shaping the number eight for 7 days just like the research conducted by Ionel et al.,13. The objective of using ligature wire is to increase the accumulation of bacteria in the gingiva that can trigger periodontitis. After 14 days of induction and acquiring the chronic periodontitis condition, the treatment groups are given the extract in accordance with the dose for the respective groups.

The papaya seed ethanol extract used in this study are $200 \mathrm{mg} / \mathrm{kgBB}, 300 \mathrm{mg} / \mathrm{kgBB}$, and 400 $\mathrm{mg} / \mathrm{kgBB}$, referring to the research conducted by Amazu which stated that at the dose of 200 $\mathrm{mg} / \mathrm{kgBB}$, there is an effect of anti-inflammation for the rats as experimental animals ${ }^{10}$. The three doses given are aimed to investigate the difference between each dose toward the osteoblasts. The giving of papaya seed extract per oral is conducted for 15 days starting from the 15th day after the periodontitis induction period is over. This aligns with the study conducted by Köse et al.,18.

The variable examined in this research is the osteoblasts, which are the cell in a form of cuboid located in the bone surface. The observation of this variable is conducted on the 16th day after the papaya seed ethanol extract is given to treatment groups for 15 days. In the graphic (Figure 2), it is shown an increase of osteoblasts mean with the highest value in the group with the extract dose of $400 \mathrm{mg} / \mathrm{kgBB}$, only it has not shown a significant increase. This is proven by the result of the statistical test that indicates the absence of a significant difference in the osteoblasts mean between the groups without the extract and the groups with the extracts of all doses. Yet, there is a significant difference between the control group with all other periodontitis groups. It is different from the in vitro research finding that was conducted by Kato, wherein the LPS P. gingivalis hampers the differentiation of osteoblasts in the stem cells of the human periodontal ligament ${ }^{17}$. This research finding aligns with that of Srinivasan's in which pro-inflammation cytokine, such as IL-1 $\beta$, does not only trigger bone resorption but also limit the formation of bone by hampering the coupling process and can trigger osteoblasts apoptosis and osteoblasts differentiation ${ }^{19}$.

One of the pathogenesis in periodontitis is the production of reactive oxygen species (ROS) by PMN (polymorphonuclear) cells as a response toward the attack of pathogenic bacteria. The imbalance between the production of free radical and local antioxidant causes periodontal tissue damage and an increase in oxidative stress. The high ROS causes free radical homeostasis and disturbs oxidative stress. The food materials that 
contain flavonoids can prevent the spread of inflammation to the whole body $5,8,12$.

Cells need an adequate antioxidant to be able to prevent tissue damage caused by the excessive production of ROS, therefore, it needs additional antioxidant from external. The study conducted by Bansal et al. stated that the assumption of high antioxidant food can decrease the depth of periodontal pocket as much as third times compared to merely by the mechanical therapy of scaling and root planning. Observation of the possibility of the presence of antioxidant in the healing of periodontitis is recommended to increase the assumption of nutrition with high antioxidant. Flavonoids can also restore alveolar bone density by preventing bone resorption ${ }^{5,8}$.

Polyphenol that tends to be contained by food plant is a major group of the phytochemicals with a wide range of potentials in terms of prevention and cure of diseases, therefore, it has an ability to act as an anti-inflammation and antioxidant ${ }^{5}$.

Osteoblasts influence the regulation of osteoclastogenesis through the regulation system of OPG/RANKL/RANK. OPG is known as an essential differentiation factor of the osteoclast. RANKL activates the osteoclastogenesis through its link to RANK, meanwhile, OPG can hamper the activation of osteoclasts and increase osteoclasts apoptosis. Among some polyphenols which working mechanism are proven through the system of OPG/RANKL/RANK is the isoflavone that eventually influences the relationship between osteoblasts and osteoclasts. The polyphenol effect toward osteoblasts predominantly uses pure molecule, however, individuals cannot consume polyphenol within isolate molecules but in a form of fruits and vegetables that are rich of polyphenols ${ }^{20,21}$. The polyphenols in the papaya seed ethanol extract in this study are not in the form of pure isolate and are unknown in terms of its active compound contents of phenolics, alkaloid, and flavonoids in it.

In the dose analysis, it is acknowledged that there is an influence of the difference in doses of the papaya seed ethanol extract given to the osteoblasts mean. The higher the dose, the higher the responses of each variable will be, this indicates the pharmacology effects of the papaya seed ethanol extract.

\section{CONCLUSION}

According to the research findings, it can be concluded that the papaya seed ethanol extract has a role in the healing of periodontal tissue of periodontitis rats. This is indicated by the increase in the number of osteoblasts. The giving of the papaya seed ethanol extract in a couple of different doses gives different effects to the number of osteoblasts of the periodontitis rats. The higher the dose of the papaya seed ethanol extracts given, the higher the number of the osteoblasts will be. In this study, the true percentage of the active compound contents of phenolics, alkaloid, and flavonoids in the papaya seed ethanol extract is unknown, therefore, the working mechanism proposed is hypothetical, with some other possible factors that have a role in the healing of the anti-inflammatory tissues of the periodontitis rats. Regarding the fact that there are still many factors about the papaya seed ethanol extract that have not been much explored, including its application to a wider scope of periodontitis therapy, it is recommended to further research the papaya seed ethanol extract.

\section{ACKNOWLEDGMENT}

The authors report no conflict of interest and the article is not funded or supported by any research grant.

\section{REFERENCES}

Dhotre PS.,Suryakar AN., Bhogade RB., 2012, Oxidative Stress in Periodontitis, Eur J Gen Med;9(2):81-84.

Hajishengallis G. 2015, NIH Public Access.;35(1):311. plus J Dent Res 92(8):702-708, 2013.

Yoshida M, Akagawa Y., 2011,The relationship between tooth loss and cerebral stroke. Jpn Dent Sci Rev [Internet]; 47(2):157-60. Available from: http://dx.doi.org/10. 1016/j.jdsr.2011.01.001.

Najeeb S, Zafar MS, Khurshid Z, Zohaib S, Almas K.,2016, The role of nutrition in periodontal health: an update. Nutrients. Aug 30;8(9):530.

Kala BS, Gunjan C, Disha N, Shobha P.,2015, Treatment of periodontal disease-a herbal approach. Int. J. Pharm. Sci. Rev. Res.;33:12636.

Tapsoba H, Deschamps JP.,2006, Use of medicinal plants for the treatment of oral diseases in Burkina Faso. J Ethnopharmacol.104(12):68-78.

Kothari V, Seshadri S.,2010, Antioxidant activity of seed extracts of Annona squamosa and Carica papaya. Nutr Food Sci [Internet]. 40(4):403-8. Available from: http:// www.emeraldinsight.com/doi/10.1108/00 346651011062050.

Bansal N\& Gupta N.,2014, Role Of Dietary Antioxidants In Periodontitis: A Preventive Approach. IOSR Journal of Dental and Medical Sciences. 13. 81-84. 10.9790/085313968184. 
Rahman I, Biswas SK, Kirkham PA.,2006, Regulation of inflammation and redox signaling by dietary polyphenols. Biochem Pharmacol.;72(11):1439-52.

Amazu LU, Azikiwe CCA, Njoku CJ, Osuala FN, Nwosu PJC, Ajugwo AO, et al.,2010, Antiinflammatory activity of the methanolic extract of the seeds of Carica papaya in experimental animals. Asian Pac J Trop Med.;3(11):884-6.

Hienz SA, Paliwal S, Ivanovski S., 2015, Mechanisms of bone resorption in periodontitis. J Immunol Res.;http:// dx.doi.org/10.1155/2015/615486

Chen $\mathrm{D}^{1}$, Nie M, Fan MW, Bian Z., 2008, Antiinflammatory activity of curcumin in macrophages stimulated by lipopolysaccharides from Porphyromonasgingivalis. Pharmacology, 82(4):264-9. doi: 10.1159/000161127.

Ionel A, Lucaciu O, Moga M, Buhatel D, Ilea A, Catoi C, et al. 2015, Periodontal disease induced in Wistar rats - experimental study. Hum Vet Med Int J Bioflux Soc. 7(2):90-5.

Peter JK, Kumar Y, Pandey P, Masih H. 2014, Antibacterial Activity of Seed and Leaf Extract of Carica Papaya var. Pusa dwarf Linn. IOSR J Pharm Biol Sci [Internet]. 9(2):29-37. Available from: http://www. iosrjournals.org/iosrjpbs/zpapers/Vol9issue2/Version7/F09272937. pdf.

Wulansari DD, Basori A, Suhartati S., 2017, Trad. Med. J., May - August Vol. 22(2), p 131-138.

Fuadiyah D, Ratnawaty R, Soebijakto BA.,2017, Pengaruh lama paparan lps (lipopolisakarida) phorpyromonas gingivalis sebagai induktor periodontitis terhadap kadar ldl dan hdl tikus wistar (rattus norvegicus), e-prodenta, vol 1, no 2 pp. 54-67.

Kato H, Taguchi Y, Tominaga $\mathrm{K}$, Umeda M, Tanaka A., 2014, Porphyromonas gingivalis LPS inhibits osteoblastic differentiation and promotes pro-inflammatory cytokine production in human periodontal ligament stem cells. Arch Oral Biol [Internet].59(2):167-75. http://dx.doi.org/ 10.1016/ j.archoralbio.2013.11.008.

Köse 0, Arabaci T, Kizildag A, Erdemci B, Özkal Eminoğlu D, Gedikli S, et al. Melatonin prevents radiation-induced oxidative stress and periodontal tissue breakdown in irradiated rats with experimental periodontitis. J Periodontal Res. 2017;52(3):438-46.

Srinivasan PC. 2013; The Role of Inflammatory Cytokines and the RANKL-RANK-OPG Molecular Triad in Periodontal Bone Loss-A Review. J Clin Cell Immunol [Internet]. Available from: https://www.omicsonline .org/ the - role - of - inflammatory cytokines - and - the - ranklrankopg molecular - triad - in - periodontal- bone loss-2155-9899.S13-007.php?aid=19772.

Azhar IS, Kresnoadi U, Rahayu RP. 2017;Potency of Garcinia mangostana $L$ peel extract combined with demineralized freeze-dried bovine bone xenograft on IL-1 $\beta$ expression, osteoblasts, and osteoclasts in alveolar bone. Dent J (Majalah Kedokt Gigi). 50(32):166-70.

Trzeciakiewicz A, Habauzit V, Horcajada MN, 2009; When nutrition interacts with osteoblast function: Molecular mechanisms of polyphenols. Nutr Res Rev. 22(1): 68-81. 